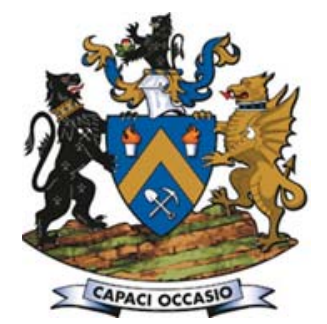

\title{
Acid-base accounting of unburned coal from underground coal gasification at Majuba pilot plant
}

\author{
by L.S. Mokhahlane, M. Gomo, and D. Vermeulen
}

\section{Synopsis}

Underground coal gasification (UCG) is an unconventional mining method that converts coal in situ into a fuel gas that can be used for electricity generation. Residue products from UCG have the potential to leach into surrounding groundwaters. The geochemistry and leaching dynamics of these products are explored in this study. The products include char, ash, and the heat-affected zone in the surrounding rocks. Core samples from the pilot plant at Majuba are the first ever to be recovered from a UCG cavity in Africa, and they give key insights into the geochemistry of the gasification zone. Mineralogical and chemical analyses were performed on the samples, and acid-base accounting $(\mathrm{ABA})$ was used to predict the acid-producing capacity of the gasification zone, particularly for char samples. Some of the char contained pyrite, although not all samples were acid-producing as determined by the ABA analysis. The ABA results showed that some of the unburned coal has moderate levels of sulphur, which could be the driving medium for acidic conditions. The ABA analysis indicated that water in contact with the gasification zone would eventually have a pH lower than 7 , which could lead to acid rock drainage. These results form part of a preliminary investigation into the geochemistry of the reaction zone, post gasification.

Keywords

underground coal gasification, residue products, geochemistry, acid-base accounting. exposure of sulphide minerals to water, air, and bacteria (Simate and Ndlovu, 2014). At the Majuba pilot plant, the unburned coal remaining in the cavity has been in contact with groundwater since the gasifier was shut down in 2013. It is possible that in a commercial UCG plant, most of the coal will be consumed and no unburnt coal will be left in the cavity. Most of the sulphur will be converted to $\mathrm{H}_{2} \mathrm{~S}$ during the gasification process and transported with the syngas to surface, where it can be removed and captured as elemental sulphur.

The Majuba pilot gasifier was extinguished by injecting water from the surface into the gasification zone. This method of quenching depends on the hydrogeological conditions, as highly permeable strata may not need assisted quenching. Post gasification, the groundwater level will eventually rebound and water will begin to flow through the cavity (Liu et al., 2007); this, however, depends on the permeability of the surrounding strata and extend of the UCG workings. The geochemical interactions in the cavity have the potential to generate ARD, especially if the sulphide quantities are adequate for acid generation. Equation [1] shows the reaction for oxidation of pyrite, which leads to acid generation:

$$
\begin{aligned}
& 2 \mathrm{FeS}_{2}(\mathrm{~s})+7 \mathrm{O}_{2}(\mathrm{~g})+2 \mathrm{H}_{2} \mathrm{O}(\mathrm{l}) \rightarrow \\
& 2 \mathrm{Fe}^{2+}(\mathrm{ag})+4 \mathrm{SO}_{4}^{2-}(\mathrm{aq})+4 \mathrm{H}^{+}(\mathrm{aq})
\end{aligned}
$$

This reaction produces ferrous iron, sulphate ions, and acid. The ferrous iron can further be oxidized to ferric iron by the following reaction:

$$
\begin{aligned}
& 4 \mathrm{Fe}^{2+}(s)+\mathrm{O}_{2}(g)+4 \mathrm{H}^{+}(a q) \rightarrow \\
& 4 \mathrm{Fe}^{3+}(a q)+4 \mathrm{SO}_{4}^{2-}(a q)+2 \mathrm{H}_{2} \mathrm{O}(l)
\end{aligned}
$$

* Institute for Groundwater Studies, University of the Free State.

(C) The Southern African Institute of Mining and Metallurgy, 2018. ISSN 2225-6253. Paper received Apr. 2018; revised paper received Jul. 2018. 


\section{Acid-base accounting of unburned coal from underground coal gasification at Majuba pilot plant}

In environments with low oxygen concentrations, Reaction [2] will occur only when the pH reaches 8.5 (Simate and Ndlovu, 2014). The UCG cavity post-gasification is likely to be a low-oxygen environment, unlike in conventional mining where the coal seam is in contact with the atmosphere in open pit mining and some underground mines. While oxidation of sulphide minerals contributes to the acidity of rock drainage, dissolution of carbonate minerals plays a role in neutralizing the acid via the following reaction:

$$
\mathrm{CaCO}_{3}(s)+\mathrm{H}^{+}(a q) \rightarrow 3 \mathrm{HCO}_{3}^{-}(a q)+\mathrm{Ca}^{2+}(a q)
$$

The dissolution rates of dolomite and magnesite are much slower than that of calcite (Lapakko et al., 1999). Acid generation is hence a dynamic process that needs monitoring over a long period of time.

The potential for acid generation from strata disturbed by mining activities is regulated by guidelines from the South African's Department of Water Affairs and Sanitation (Best Practice Guideline G4: Impact Prediction, Department of Water Affairs and Forestry 2008). The guideline uses the source-pathway-receptor model for its risk-based approach to impact prediction. Underground mine voids are identified as potential risk sources for water bodies. Underground coal gasification creates a cavity or void that contains residue products such as ash, char, and the heat-affected zone in the surrounding rocks. According to the G4 guideline, all these products will have to undergo geochemical assessment, including evaluation of the risk of acid generation and the potential for leaching of metals.

There are two types of laboratory tests that can be used for the prediction of acid rock drainage - static and kinetic tests. Static tests include acid-base accounting (ABA), which is relatively quick and simple to carry out while the kinetic tests, such as leaching tests, usually take longer to complete. Kinetic tests also require larger samples and are usually carried out to determine the leachate quality and long-term ARD risk. Acid-base accounting is described by Sobek et al. (1978) as predictive tool that accounts for the balance between the acid-producing potential (AP) and the neutralizing potential (NP) of geological material; the difference is calculated as the net neutralizing potential (NNP). The acid-producing material is generally the sulphide minerals (Equation [1]), while the acid-neutralizing minerals are carbonate minerals such as calcite, dolomite, and magnesite (see Equation [2]). Dissolution of some silicate minerals such as anorthite can also neutralize acid. However, silicates dissolve more slowly than their carbonate counterparts (Lapakko et al., 1999).

In UCG, ARD has the potential to weaken the infrastructure around the gasification zone as the production and injection wells are installed using cement and steel casing. The geochemistry of the surrounding aquifers can also be altered as metals become more soluble in acidic conditions, ultimately leading to ARD into the surrounding strata. The objective of this paper is to explore the leaching dynamics and geochemistry of the unburned coal from the UCG process.

\section{Site location and geological setting}

The Eskom UCG pilot plant near Majuba power station in Mpumalanga Province, South Africa, has completed phase 1 of gasification. This is the first UCG plant in Africa and had already produced fuel gas and successfully co-fired this gas with coal in a pulverized coal boiler at Majuba power station by 2010 (Pershad, Pistorius, and van der Riet, 2018). Gasification has ceased and verification drilling has commenced into the gasification zone. Verification boreholes are wells that are core-drilled into the gasification zone to establish the extent of gasification with the aim of retrieving core samples containing residue products. The verification boreholes were sited at strategic locations within the gasification panel. G1VTH1 was the first verification borehole to be drilled, and its location is shown in Figure 1.

The targeted coal-bearing formation for gasification is the Gus seam in the Vryheid Formation of the Ecca Group. The Gus seam varies from 1.8 to $4.5 \mathrm{~m}$ in thickness and at the Majuba UCG site it is found at a depth of around $280 \mathrm{~m}$. Other coal seams encountered in the area are usually laterally impersistent and serve as marker seams - they are not targeted for gasification. Coal has a lower density than the Karoo sediments (alternating sandstones and shales), as seen in the wireline log in Figure 2. The sharp density spikes from the top to bottom of the log represent the Eland, Fritz, Alfred, and Gus seams respectively. The main economic Gus seam is thicker than the other seams, with alternating sequences of bright and dull coal. The bright coal has a lower density than the dull coal. The coal zone also contains several thin $(5-20 \mathrm{~cm})$ laterally impersistent bright coal layers (the Eland and Fritz coal seams) above the Gus seam, which are used as marker seams (de Oliveira and Cawthorn, 1999).

\section{Methodology}

G1VTH1 was percussion-drilled from surface to $200 \mathrm{~m}$, and then core-drilled to just below the targeted Gus seam $(286 \mathrm{~m})$. The core samples were placed in trays and fragments of the recovered char from the Gus seam were taken (red blocks in Figure 2) for acid-base accounting. No ash was recovered, and this might be due to soft materials being washed away during drilling, as core drilling uses fluid circulation to remove the cuttings from the core barrel.

Acid-base accounting is a predictive tool used to assess the acid-producing capacity of coal mines and rock waste, in which the acid-neutralizing potential $(N P)$ and acidproducing potential $(A P)$ of rock samples are determined and the difference, the net neutralizing potential $(N N P)$, is calculated as follows:

$$
N N P=N P-A P
$$

The $A P$ is based on the theoretical oxidation of all sulphur in the sample to sulphuric acid. The total sulphur in the samples was determined using a LECO sulphur analyser. The $A P$ is generally expressed in kilograms of $\mathrm{CaCO}_{3}$ per ton of material. The conversion factor is $31.25 \mathrm{~kg} \mathrm{CaCO}_{3}$ per ton, i.e.:

$A P=$ sulphur content $(\%) \times 31.25 \mathrm{~kg} \mathrm{CaCO}_{3}$ equivalent per ton.

The dissolution of acid-neutralizing minerals such as carbonates contributes towards the NP. Hydrochloric acid is used to sufficiently digest these minerals and the $N P$ is expressed in $\mathrm{kg} \mathrm{CaCO}_{3}$ per ton, but it can also be converted into acid-neutralizing capacity (ANC, expressed as kilograms $\mathrm{H}_{2} \mathrm{SO}_{4}$ per ton) by multiplying the NP by 0.98 . 
Acid-base accounting of unburned coal from underground coal gasification at Majuba pilot plant

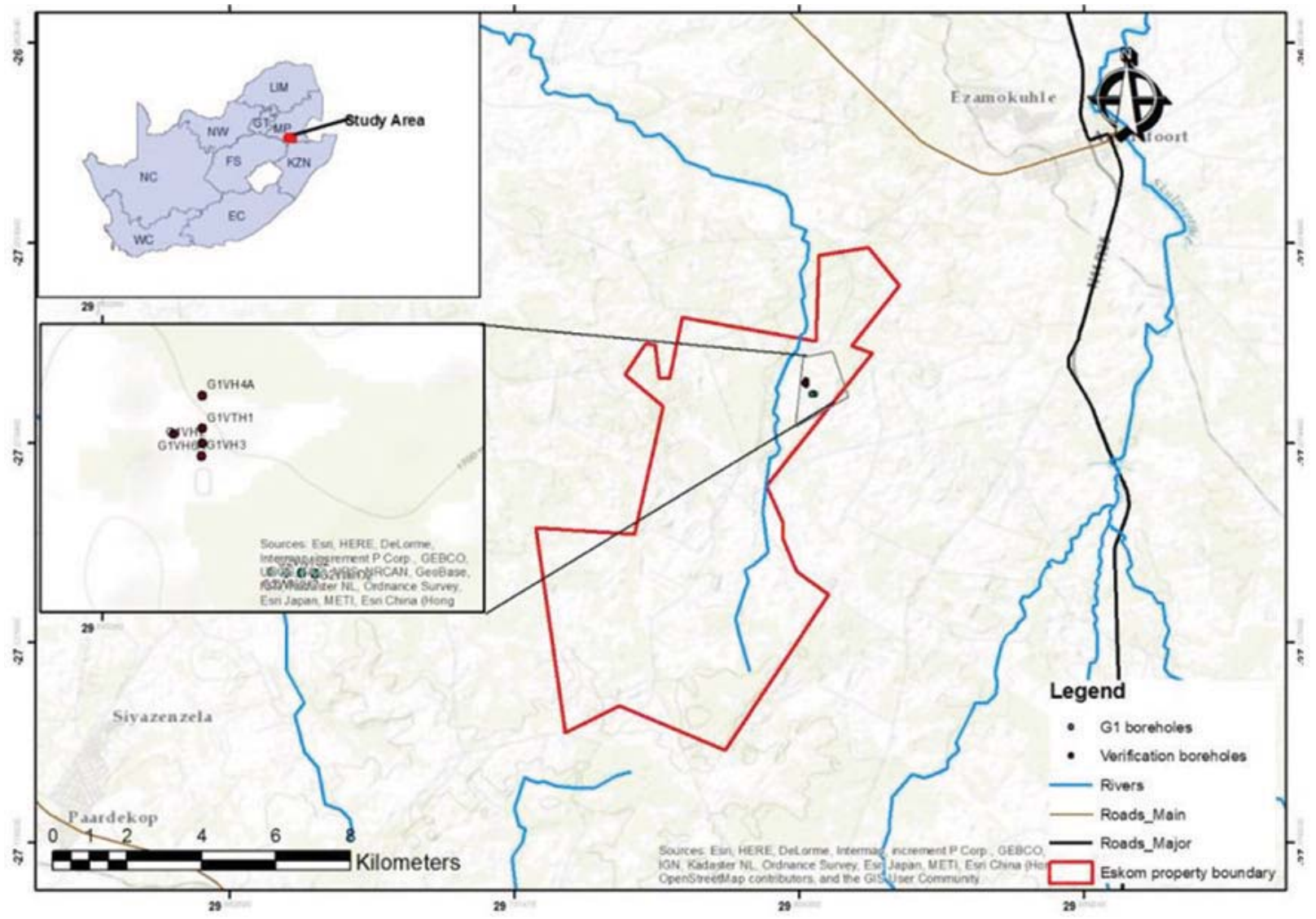

Figure 1-Majuba UCG pilot plant location

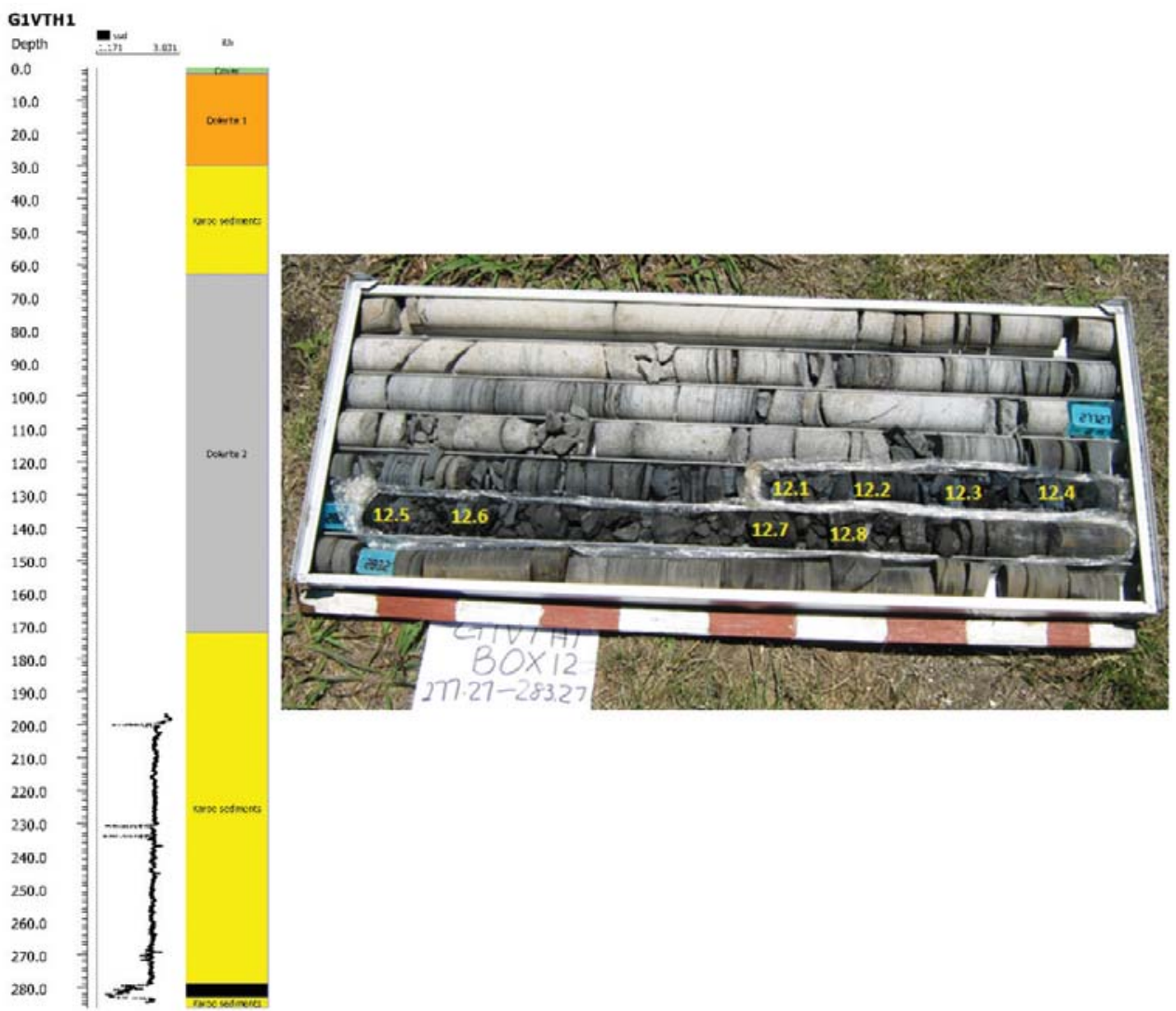




\section{Acid-base accounting of unburned coal from underground coal gasification at Majuba pilot plant}

Negative $N N P$ values indicate the potential for acid generation, while positive $N N P$ values are associated with alkaline conditions. However, a NNP of more than 20 is generally required before non-acid conditions can be declared. There is, therefore, a region of uncertainty from -20 to $+20 \mathrm{~kg} \mathrm{CaCO}_{3} N N P$, which usually requires kinetic testing if the ABA results are inconclusive (Qureshi, Maurice, and Öhlander, 2016). The ratio of $N P$ to AP, known as the neutralization potential ratio (NPR), can also be used to determine the potential for acidic conditions. Materials with a NPR of 2.5 are regarded as non-acid-producing, and those with NPR of 1 as acid-producing, while the uncertain region is between 1 and 2.5 (Qureshi, Maurice, and Öhlander, 2016).

Mineralogical compositions were determined using the QEMSCAN (Quantitative Evaluation of Minerals by Scanning Electron Microscopy) technique. The QEMSCAN is a scanning electron microscope-based system configured to automatically determine the mineralogical characteristics of particulate samples. Samples were also leached using water, acid, and hydrogen peroxide to determine the leaching

Table I

\section{Analysis of unburned coal from the gasification zone (wt. \%)}

\begin{tabular}{|l|c|c|c|c|c|}
\hline Sample & Moisture & Ash & Volatile matter & Fixed carbon & Total sulphur \\
\hline 12.1 & 5.3 & 46.9 & 3.7 & 44.1 & 0.41 \\
12.2 & 6.4 & 63.6 & 5.6 & 24.4 & 0.35 \\
12.3 & 5.7 & 47.9 & 4.4 & 42.0 & 0.46 \\
12.4 & 5.4 & 50.3 & 4.4 & 39.9 & 0.47 \\
12.5 & 4.5 & 69.4 & 5.5 & 20.6 & 0.21 \\
12.6 & 4.7 & 40.1 & 3.7 & 51.5 & 0.53 \\
12.7 & 4.3 & 39.7 & 1.7 & 54.3 & 1.4 \\
12.8 & 4.4 & 10.4 & 2.7 & 82.5 & 0.57 \\
\hline
\end{tabular}

dynamics in different environments. The water leach test is carried out over 24 hours using $50 \mathrm{ml}$ of demineralized water to $5 \mathrm{~g}$ solid material. The peroxide leach test is carried out over 24 hours using hydrogen peroxide at $2 \mathrm{~g}$ solid material to $80 \mathrm{ml}$ hydrogen peroxide. The acid leach test is carried out over 24 hours using $5 \mathrm{~g}$ solid material and $50 \mathrm{ml}$ of approximately $0.1 \mathrm{~N}$ sulphuric acid. All the leachates were analysed using inductively coupled plasma mass spectrometry (ICP-MS).

\section{Results and discussion}

The proximate and sulphur analyses were carried out at the Eskom Research, Testing and Development (RT\&D) laboratory in Johannesburg. The results for the char samples from the gasification zone are presented in Table I. The total sulphur values were used in the ABA analysis to determine the long-term risk of acid production.

The mineralogical results from QEMSCAN are presented in Table II. The samples were taken from both the Gus and the Alfred seams as they occurred close together in G1VTH1. The unburned coal recovered is shown in Figure 2, with the density log displayed. The down-the-well density log shows that low-density bright coal is situated towards the bottom of the seam while the dull coal is found predominantly in the upper parts of coal seam (Alfred and Upper Gus). A 3.16 m core loss was recorded from 280-286 m.

The mineralogical analyses are of the residual material after UCG, and due to absence of such detailed analyses prior to UCG they cannot be proportioned to the initial mineral composition. The mineralogical results show that all of the char samples from the Gus seam contain pyrite, which is the major contributor to ARD (Table II). Carbonate minerals, including calcite and siderite, were identified in the coal samples. Dissolution of carbonate minerals plays a role in the neutralization of acid, as seen in Equation [3]. Some of the silicate minerals found in the samples also contribute to neutralization reactions.

Table II

Mineralogical results from QEMSCAN (wt. \%)

\begin{tabular}{|c|c|c|c|c|c|c|c|c|}
\hline & \multicolumn{4}{|c|}{ Alfred seam } & \multicolumn{4}{|c|}{ Gus seam } \\
\hline & 12.1 & 12.2 & 12.3 & 12.4 & 12.5 & 12.6 & 12.7 & 12.8 \\
\hline Pyrite & 0 & 0 & 0 & 15.2 & 0.2 & 4 & 0.4 & 0.4 \\
\hline Oxidized pyrite & 0 & 0 & 0 & 4.8 & 0 & 1.3 & 0.1 & 0.1 \\
\hline Siderite & 0 & 0.2 & 0 & 32 & 2.4 & 0.4 & 0.3 & 0.1 \\
\hline Calcite & 0 & 0 & 0 & 0.7 & 0.1 & 0.4 & 1 & 0.2 \\
\hline Dolomite & 0 & 0 & 0 & 1.3 & 0 & 0 & 0 & 0 \\
\hline Gypsum & 0 & 0 & 0 & 0.6 & 0 & 0 & 0 & 0 \\
\hline Apatite & 0 & 0 & 0 & 0 & 0 & 0 & 0 & 0 \\
\hline Ca-Mg-(Al) silicate & 1.1 & 4.3 & 0.6 & 12.8 & 4.7 & 5.1 & 6.3 & 0.1 \\
\hline Ca-Al silicate & 11 & 11 & 3.6 & 2 & 9.4 & 3.3 & 5.9 & 0.9 \\
\hline Kaolinite & 38.6 & 30.9 & 51.8 & 8.9 & 20.3 & 13 & 15.3 & 1.7 \\
\hline Quartz & 11.5 & 17.2 & 18.5 & 5.5 & 8 & 5.8 & 4.5 & 0.2 \\
\hline Mica/illite & 12.9 & 3.8 & 5.7 & 4.2 & 6.2 & 0.4 & 0.7 & 0 \\
\hline Microcline & 2 & 0.8 & 1.4 & 1.5 & 1.1 & 0 & 0 & 0 \\
\hline Rutile & 0.1 & 0.1 & 0 & 0.2 & 0.1 & 0.1 & 0 & 0 \\
\hline Alunite/gibbsite & 0.1 & 0.5 & 0.1 & 0 & 0.6 & 0.3 & 0.2 & 0.1 \\
\hline Vitrinite & 5.4 & 15.9 & 4.3 & 5.9 & 22.2 & 4 & 1.2 & 12.1 \\
\hline Semi-fusinite & 8 & 5.7 & 6.8 & 2.1 & 11.6 & 17.2 & 17.4 & 15.1 \\
\hline Fusinite & 9.4 & 9.6 & 7.2 & 2.1 & 13.1 & 44.8 & 46.6 & 68.9 \\
\hline
\end{tabular}




\section{Acid-base accounting of unburned coal from underground coal gasification at Majuba pilot plant}

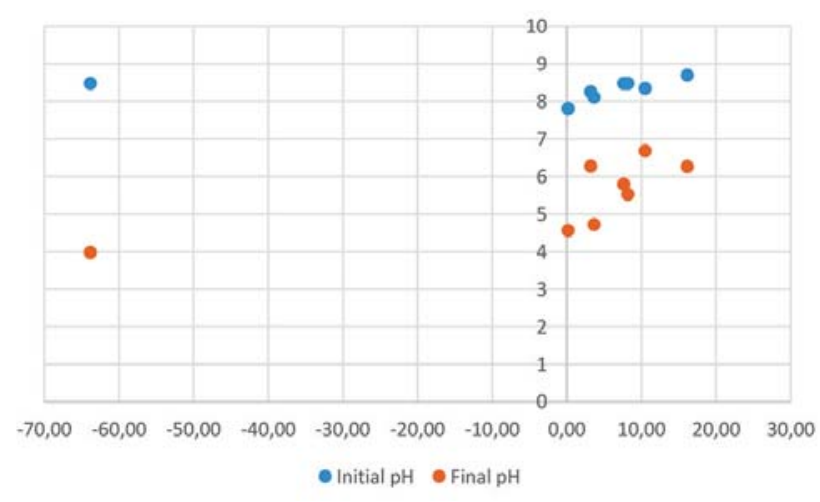

Figure $3-\mathrm{pH}$ as a function of net neutralizing potential

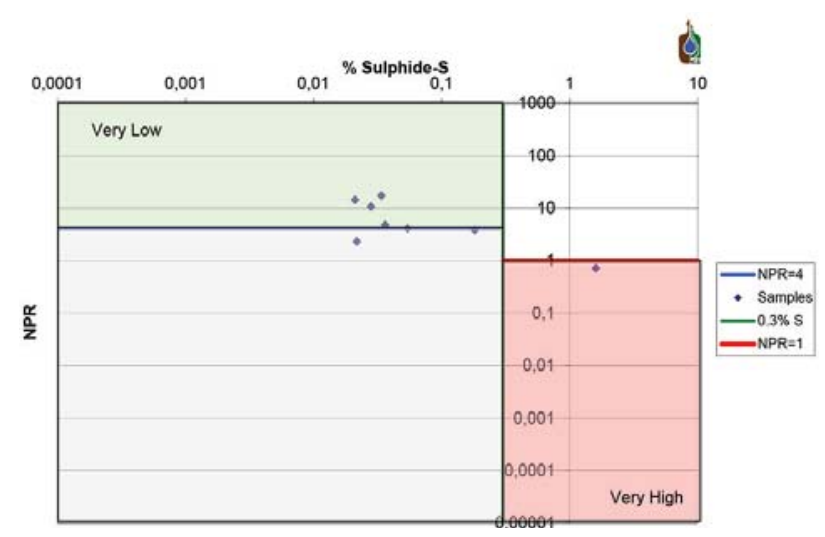

Figure 4-Neutralization potential ratio (NPR) as a function of sulphide content

The initial pH of the samples was above 7 , as seen in Figure 3. The $N N P$ was positive for all the samples except one. A positive $N N P$ indicates non-acid-generating material whereas a negative $N N P$ is associated with potentially acidgenerating material. Sample 12.7 had a NNP of -63.78 , which may be largely due to the higher levels of sulphur in this sample (1.4 wt.\%) (Table I). This is more than twice the amount of sulphur in all the other samples. The final $\mathrm{pH}$ of this sample was also the lowest of all the samples which, together with the elevated pyrite content, indicates a high potential for acid generation.

The majority of the results in Figure 3 fall into the uncertainty region of -20 to +20 NNP. Although these samples have positive NNPS they cannot be conclusively regarded as non-acid-producing. The neutralization potential ratio (NPR) was used to determine the long-term acid production potential of the samples, as shown in Figure 4. The graph is divided into regions representing the likelihood for acid generation. The 'very low' region represents samples that are non-acid-producing while the 'very high' region represents acid-generating samples. The uncertain region is represented by the blue region under the 'very low' region. A NPR greater than 2.5 normally points to non-acid generation, while a NPR less than 1 indicates acid production if the sulphur content is also above $0.3 \mathrm{wt} . \%$. The NPR results shown in Figure 4 indicate that only sample 12.7 has the potential for acid generation, as was indicated in Figure 3.
The majority of the samples are non-acid-generating, with only one in the uncertain region. The general trend of the char samples taken from the gasification zone is that of nonacid-producing materials.

ARD is associated with iron being released into solution, as seen in Equations [1] and [2]. The leaching dynamics of the samples is shown in Figure 5. Very little Fe is released from the char samples when using demineralized water as a leaching medium. The same trend is seen when leaching is carried out under oxidizing conditions using hydrogen peroxide, with insignificant Fe being released. Under acidic conditions, Fe is released in greater quantities than under oxidizing conditions. Sample 12.7 released more Fe than any other char sample, which is consistent with the ABA and mineralogical analyses.

The leaching results show a similar trend as the ABA, where only one sample was considered as acid-producing. The general trend in Fe release also shows the same sample releasing higher amounts of Fe as compared to other samples. The highest levels of sulphur were also found in the same sample. This affirms that for acid generation to occur, an adequate quantity of sulphur has to be available to sustain the acidic conditions. The majority of samples did not show a tendency to leach high levels of Fe under different conditions.

The results show that even if the general conditions in the gasification zone become more oxidizing, the leaching dynamics for Fe may still be low. Groundwater will be the leaching medium for the unburned coal and much of the leaching behaviour will also depend on the chemistry of the local groundwater

\section{Conclusions}

The study gives key insights into the geochemistry of the gasification zone of the underground coal gasification project. The major conclusion is that the char does not pose an immediate of ARD formation, except for one sample. The geochemistry of the char samples shows the heterogeneous nature of coal in terms of mineralogical and chemical properties. More iron was leached under acidic conditions from samples with high levels of sulphur. Groundwater will be the leaching medium for the unburned coal and the leaching behaviour will depend on the chemistry of the local groundwater. It is possible that in a commercial UCG plant, most of the coal will be consumed and no unburnt coal will be left in the cavity. Most of the sulphur will be converted to

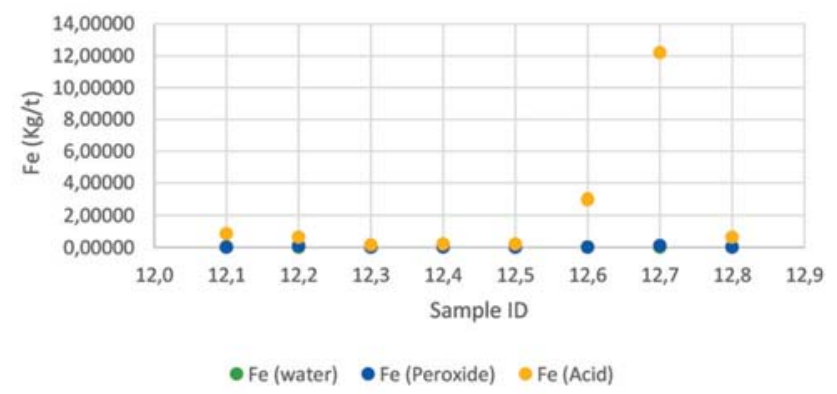

Figure 5-Leaching dynamics of $\mathrm{Fe}$ in water, hydrogen peroxide, and acid 


\section{Acid-base accounting of unburned coal from underground coal gasification at Majuba pilot plant}

$\mathrm{H}_{2} \mathrm{~S}$ during the gasification process and transported with the syngas to the surface, where it can be removed and captured as elemental sulphur. The coal seam at Majuba is at a depth of around $280 \mathrm{~m}$ below the ground level and the geohydrological conditions show no interaction between the coal seam aquifer and the shallow aquifer. Contamination of the shallow aquifer from any potential post-gasification acid rock drainage that may be generated in the UCG cavity is therefore unlikely.

\section{References}

BhutTo, A.W., BAzmi, A.A., and ZAhEdi, G. 2013. Underground coal gasification: From fundamentals to applications. Progress in Energy and Combustion Science, vol. 39, no. 1. pp. 189-214.

Bouzahzah, H., Benzaazoua, M., Plante, B., and Bussiere, B. 2015. A quantitative approach for the estimation of the 'fizz rating' parameter in the acid-base accounting tests: A new adaptations of the Sobek test. Journal of Geochemical Exploration, vol. 153. pp. 53-65.
De Oliveira, D.P.S. and CAWTHoRn, R.G. 1999. Dolerite intrusion morphology at Majuba Colliery, northeast Karoo Basin, Republic of South Africa. International Journal of Coal Geology, vol. 41, no. 4. pp. 333-349.

Kefeni, K.K., Msagati, T.A.M., and Mamba, B.B. 2017. Acid mine drainage: Prevention, treatment options, and resource recovery: A review. Journal of Cleaner Production, vol. 151. pp. 475-493.

Liu, S.-Q., LI, J.-G., MEI, M., and Dong, D.-L. 2007. Groundwater pollution from underground coal gasification. Journal of China University of Mining and Technology, vol. 17, no. 4, pp. 467-472.

Pershad, S., Pistorius, J., and van Der Riet, M. 2018. Majuba underground coal gasification project. Underground Coal Gasification and Combustion. Blinderman, M.S. and Klimenko, A.Y. (eds.). Woodhead Publishing, Cambridge, UK. pp. 469-502.

QuREShI, A., MAurice, C., and ÖHLANDER, B. 2016. Potential of coal mine waste rock for generating acid mine drainage. Journal of Geochemical Exploration, vol. 160. pp. 44-54.

Simate, G.S. and NdLovu, S. 2014. Acid mine drainage: Challenges and opportunities. Journal of Environmental Chemical Engineering, vol. 2, no. 3. pp. $1785-1803$.

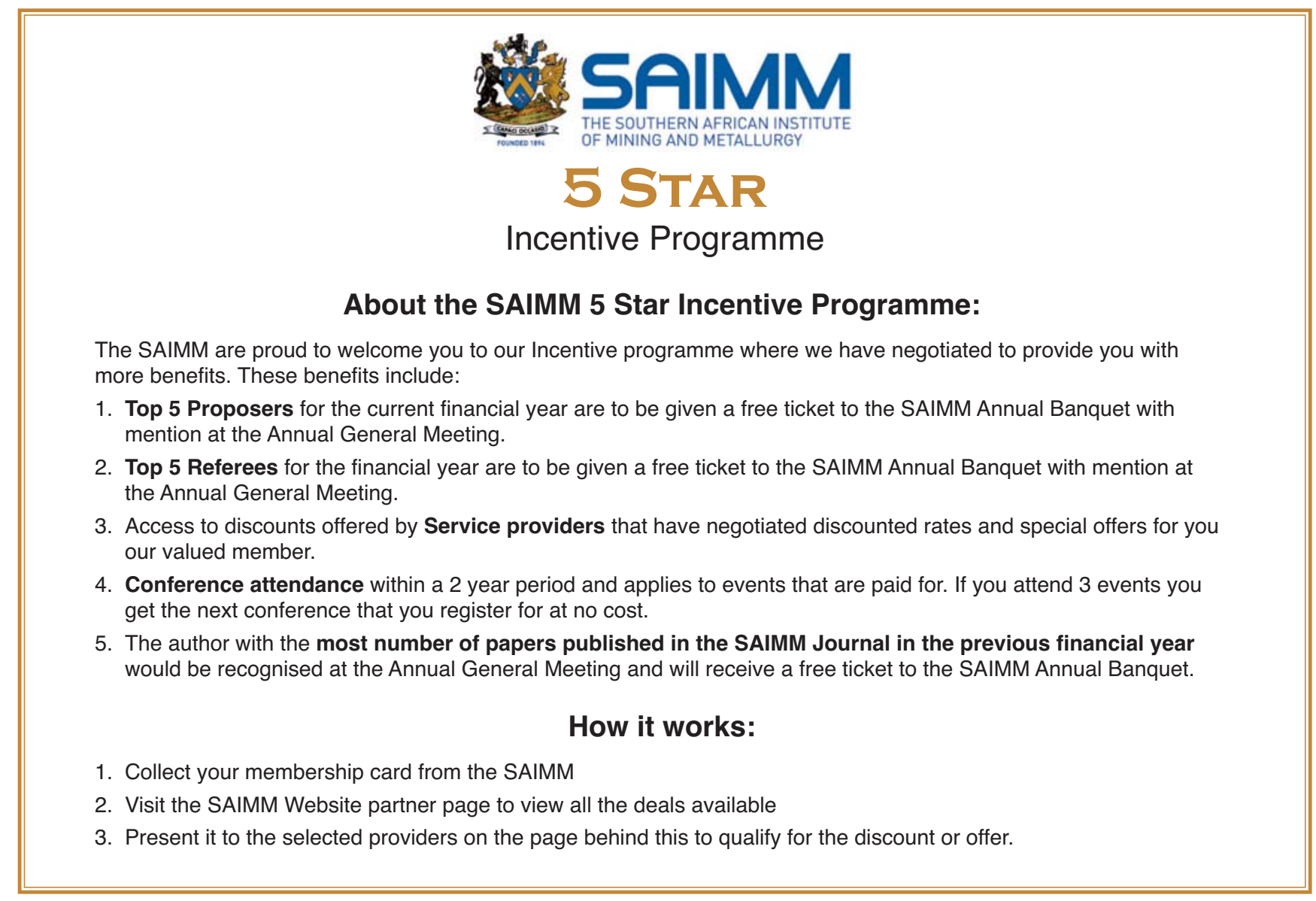

